\title{
Cosmetic Surgery as Intrasexual Competition: The Mediating Role of Social Comparison
}

\author{
Steven Arnocky, Tina Piché \\ Department of Psychology, Nipissing University, North Bay, Canada \\ Email: stevena@nipissingu.ca
}

Received 10 June 2014; revised 8 July 2014; accepted 1 August 2014

Copyright (C) 2014 by authors and Scientific Research Publishing Inc.

This work is licensed under the Creative Commons Attribution International License (CC BY).

http://creativecommons.org/licenses/by/4.0/

cC) (7) Open Access

\begin{abstract}
Cosmetic surgical procedures have previously been associated with some risks to psychological and physical health. Yet such procedures are on the rise, highlighting the need for a better understanding of the factors which might underlie the decision to undergo cosmetic surgery. In a sample of 297 young adults (192 women), we examined the relationship between intrasexual competition (IC), social comparison, and individuals' attitudes, perceived risks, and desired spending on cosmetic surgical procedures. Results showed that women perceived more risk to cosmetic surgery, yet held more positive attitudes and desire to spend on cosmetic surgery compared to men. For both men and women, IC predicted positive attitudes and desired spending on cosmetic surgery. Social comparison mediated all relationships between IC and cosmetic surgery variables. Cosmetic surgery is discussed as a potential form of intrasexual competition rooted in the mate-preferences of the opposite sex.
\end{abstract}

\section{Keywords}

Intrasexual Competition, Cosmetic Surgery, Dishonest Signalling, Signalling Theory, Social Comparison

\section{Introduction}

Cosmetic medical procedures are on the rise, with over 15 million performed in the United States in 2013-an increase of approximately half a million since 2012 (American Society for Plastic Surgeons, 2013). This rapid growth may reflect the public's budding acceptance of cosmetic procedures as a form of self-improvement (Delinsky, 2005); a mechanism through which one can enhance their quality of life (Alsarraf, Larrabee, Anderson, 
Murakami, \& Johnson, 2001; Castle, Honigman, \& Phillips, 2002), body image (Sarwer et al., 2005), and mood (Rankin, Borah, Perry, \& Weh, 1998). However, there are notable risks associated with many elective cosmetic procedures, especially with regard to invasive cosmetic surgery. Postoperative psychological consequences can include anxiety, disappointment, and depression (Borah, Rankin, \& Wey, 1999). Physical complications are not uncommon (e.g., in up to $24 \%$ of breast augmentations), and can involve scarring, infection, and bleeding (Gabriel et al., 1997). Estimates of mortality risk for cosmetic procedures range between 1 in 13,000 to 1 in 5000 cases (Grazer \& de Jong, 2000; Yoho, Romain, \& O’Neil, 2005).

Recently, advances in determining the proximate sociocultural factors underlying cosmetic surgery attitudes and decisions have emphasized the role of cultural views of femininity and power imbalance between the genders (e.g., Davis, 1995; Dull \& West, 1991), as well as the roles of personality (Swami, Chamorro-Premuzic, Bridges, \& Furnham, 2009) and individual differences in poor body image and appearance-related psychopathologies (e.g., Sarwer, Wadden, Pertschuk, \& Whitaker, 1998; Swami, 2009, 2010; Thorpe, Ahmed, \& Steer, 2004). Research has shown that those who are more invested in their physical appearance (Sarwer et al., 2005), who internalize media messages about appearance (Markey \& Markey, 2009; Swami, 2009), who are more conforming (Swami et al., 2009), who are more sensitive to rejection (Park et al., 2009), and who are more materialistic (Henderson-King \& Brooks, 2009) are all more likely to express positive attitudes toward cosmetic surgery.

Common among these potential explanations is the understanding that cosmetic surgery is undertaken in order to improve aspects of one's physical appearance-a domain that is inherently relevant to mate selection and intrasexual competition (e.g., Arnocky, Sunderani, Miller, \& Vaillancourt, 2012; Arnocky \& Vaillancourt, 2012; Sunderani, Arnocky, \& Vaillancourt, 2013). However, to date, little research has explored the potential ultimate factors associated with cosmetic surgery. The present study builds upon existing proximate explanations, by exploring cosmetic surgery from the perspective of sexual selection as a modern manifestation of intersexual and intrasexual (i.e., within-sex) selection. Intersexual selection refers to the degree of choosiness or selectivity for characteristics in potential mating partners. Intrasexual selection refers to competition between members of the same sex over contested mating resources and opportunities (e.g., Thornhill \& Alcock, 1983). These two constructs are highly related: members of one sex often compete along dimensions viewed as important mating characteristics by the opposite sex (Buss, 1988). The present study explores cosmetic surgery as one such intrasexually-competitive method-a tactic for making oneself more desirable than same-sex conspecifics to members of the opposite sex. Indeed, recent evidence suggests that hyper-competitive women hold more positive attitudes toward cosmetic surgery (Thornton, Ryckman, \& Gold, 2013). We expected that intrasexually-competitive individuals would more frequently assess where they stand on dimensions of physical attractiveness relative to others, and would in turn express more positive attitudes toward cosmetic surgery and greater desired spending on cosmetic surgery, as well as low perceived risk of cosmetic surgery compared to less intrasexually-competitive individuals.

Physical attractiveness plays an important role in mate selection. Morphological features signifying youth and health serve as visible cues to one's reproductive value and viability as a mate (Buss \& Schmitt, 1993; Henderson \& Anglin, 2003; Shackelford \& Larsen, 1999; Symons, 1979; c.f. Weeden \& Sabini, 2005). For instance, men's facial attractiveness correlates with both sperm morphology and motility (Soler et al., 2003), and both men and women with attractive faces may be healthier than their less attractive counterparts (Shackelford \& Larsen, 1999). Similarly, body size and shape are important cues to women's fertility status (Hamilton-Fairley, Kiddy, Watson, \& Franks, 1992; Singh, 1993) and likelihood of miscarriage (Metwally, Ong, Ledger, \& Li, 2008). Various dimensions of physical attractiveness have therefore been linked to mating success indices. For example, facial attractiveness has been found to correlate with women's earlier age of sexual activity and number of long-term sexual partners, as well as men's number of short-term sexual partners (Rhodes, Simmons, \& Peters, 2005).

Given the importance of physical attractiveness to mating success, it is not surprising that physical appearance-enhancement has been identified as a strategy for intrasexual competition (e.g., Buss, 1988). Interestingly, appearance-enhancement behaviors were also scored by independent raters as being more effective for women than that for men in attracting a mate (Buss, 1988). Experimental evidence has corroborated the use of appearance-enhancement (including risky behaviors) as a strategy for intrasexual competition. Hill and Durante (2011), for example, found that women primed with intrasexual competition motives expressed increased willingness to take health risks (in the form of skin-tanning and diet pill use) in order to enhance their physical appearance. In- 
trasexual competition has also been shown to correlate positively with disordered eating behavior (Abed, 1998; Faer, Hendriks, Abed, \& Figueredo, 2005; Li et al., 2010).

Cosmetic surgical procedures have indeed been shown to improve others' perceptions of one's attractiveness. For instance, women who undergo micro-fat grafting surgery effectively reduce their waist-to-hip ratio, and are rated by judges as being more physically-attractive post-operatively (Singh \& Randall, 2007). Similarly, rhinoplasty has been shown to lead to improvements in physical attractiveness which promotes more favorable ratings of one's personality by others (Cash \& Horton, 1983). We therefore expected that intrasexually-competitive attitudes would predict positive attitudes and desire to spend money on cosmetic surgery, as well as lower perceived risk regarding the safety of cosmetic surgery (H1).

Successful intrasexual competition relies upon the ability to weight the costs and benefits of competitive action. By comparing the self with others (Festinger, 1954), one can effectively determine what others will find attractive, and how one should alter their behavior in order to receive favorable attention. If individuals perceive themselves to fall short or to be otherwise insufficient on an important domain (such as physical attractiveness), various defenses or responses can be activated (Gilbert, Price, \& Allan, 1995). Indeed, intrasexually-competitive attitudes have previously been shown to correlate with social comparisons (Buunk \& Fisher, 2009), and individuals concerned by the threat of intrasexual rivals have been shown to pay more visual attention to members of one’s own sex (Maner, Gailliot, Rouby, \& Miller, 2007).

There is evidence that social comparison may influence attitudes toward cosmetic surgery. Awareness of the sociocultural emphasis on appearance, and internalization of that influence (in part through social comparisons such as "I tend to compare my body to people in magazines and on TV") have been shown to predict both cosmetic surgery attitudes and intentions (Henderson-King \& Brooks, 2009). Nabi (2009) found that viewing cosmetic surgery makeover programming led to a small increase in cosmetic surgery intentions, and that making social comparisons to the individuals featured on those shows predicted desiring invasive, minimally invasive, and noninvasive cosmetic procedures. We expected that intrasexually-competitive individuals would be more likely to make appearance-based social comparisons, and that such comparisons would mediate the relationships between intrasexual competition and positive attitudes, desired spending, and low perceived risk regarding cosmetic surgery (H2).

\section{Method}

\subsection{Participants}

Our sample consisted of 192 women and 105 men between the ages of 16 and 31( $\mathrm{M}_{\mathrm{age}}=21.35$, SD = 2.98). Participants were recruited in common areas of a mid-sized university and college. Each participant completed a paper-based questionnaire, and were compensated with a chance to win one of three $\$ 100$ draws.

\subsection{Materials}

Participants completed the 12-item scale for intrasexual competition (Buunk \& Fisher, 2009) in order to assess the degree to which one holds a competitive attitude toward members of the same sex. The measure consists of a 7-point Likert-type scale anchored at $1=$ not at all applicable to $7=$ completely applicable, along which participants indicate how true each statement is of them. Example items include: "I can't stand it when I meet another (wo)man who is more attractive than I am" and "I want to be just a little better than other (wo)men". The measure showed good internal consistency for both men $(\alpha=.89)$, and women $(\alpha=.91)$.

In order to assess the degree to which individuals compare their physical appearance to the appearance of their peers, participants completed the 5-item Physical Appearance Comparison Scale (PACS; Thompson, Heinberg, \& Tantleff, 1991). Using a 5-point Likert-type scale ranging from $1=$ never to 5 = always, participants rate the frequency with which they make comparisons such as "At parties or other social events, I compare my physical appearance to the physical appearance of others". In the present study the PACS showed acceptable internal consistency among both men $(\alpha=.70)$, and women $(\alpha=.75)$.

Participants completed the 15-item Acceptance of Cosmetic Surgery Scale (ACSS; Henderson-King, \& Henderson-King, 2005) as a measure of the degree to which favorable attitudes toward cosmetic surgery are held. Using a 7-point Likert-type scale anchored at $1=$ strongly disagree and $7=$ strongly agree, participants rated their agreement with statements surrounding their intrapersonal and social attitudes and willingness to consider cosmetic surgery. Example items include: "In the future, I could end up having some kind of cosmetic surgery"; 
"If it would benefit my career, I would think about having plastic surgery", and "If I could have a surgical procedure done for free I would consider trying cosmetic trying cosmetic surgery”. The ACSS has previously shown good test-retest reliability as well as convergent and discriminant validity (Henderson-King \& Henderson-King, 2005). In the present study, the three attitudinal subscales were combined with items averaged to create one overarching attitude toward cosmetic surgery score. The measure showed good internal consistency among both men $(\alpha=.89)$ and women $(\alpha=.92)$.

Participants were given a basic definition of cosmetic surgery along with a list of examples. Using a 6-point Likert-type scale, respondents indicated how much they would be willing to spend on cosmetic surgery over their lifetime, with response options ranging as follows: $\$ 0, \$ 1$ - \$999, $\$ 1000$ - \$4999, $\$ 5000$ - \$9999, $\$ 10,000$ $\$ 19,999$, and $>\$ 20,000$.

Perceived risk and benefits of cosmetic surgery were measured with four items, some of which were modified from a previous survey created by Nabi (2009). On a 5-point Likert scale ranging from $1=$ strongly disagree to 5 = strongly agree, participants rated the degree to which they believe that cosmetic surgery poses little health risk (i.e., "Cosmetic surgery is a low-risk way to improve one’s appearance", "Having cosmetic surgery is worth the slight risk posed to one's health", "With modern medical practices, most cosmetic surgery procedures pose almost no risk to one's health", and "Very rarely does cosmetic surgery lead to psychological trauma, injury/medical complications or death"). Items were reverse coded so that higher scores reflected greater perception of risk. Principle components analysis revealed that the four items loaded on one singular dimension with factor loadings ranging between .75 and .81 and contributed $61 \%$ toward explained variance. The measure also showed good internal consistency among both men $(\alpha=.80)$ and women $(\alpha=.79)$. Descriptive statistics for each measure are provided in Table 1.

\section{Results}

For descriptive purposes we examined sex differences in cosmetic surgery. Independent samples t-tests found that women $(\mathrm{M}=3.55 \mathrm{SD}=.49)$ more than men $(\mathrm{M}=3.35 \mathrm{SD}=.46)$ perceived there to be risk associated with having cosmetic surgery, $\mathrm{t}(1,290)=-3.35, p<.01, \mathrm{~d}=.42$. Nevertheless, women $(\mathrm{M}=2.72 \mathrm{SD}=1.39)$ also held more positive attitudes toward cosmetic surgery than did men $(\mathrm{M}=2.25 \mathrm{SD}=.95), \mathrm{t}(1,290)=-3.02, p$ $<.01, \mathrm{~d}=.39$, and women $(\mathrm{M}=1.78 \mathrm{SD}=1.14)$ intended to spend more money than men $(\mathrm{M}=1.37 \mathrm{SD}=0.85)$ on cosmetic surgery over their lifetime, $\mathrm{t}(1,290)=-3.24, p<.01, \mathrm{~d}=.41$.

We next examined the simple effects of intrasexual competition on each of the cosmetic surgery outcome variables. Bootstrapping procedures, as outlined by MacKinnon et al. (2002), were then used to examine the mediating role of physical appearance comparison to these relationships, whereby the mediated effect is the reduction of the link between the predictor variable and the criterion upon inclusion of the mediating variable (Baron \& Kenny, 1986). For each analysis in the present study, 1000 bootstrapping samples were derived. All coefficients reported herein are unstandardized.

In order to test physical appearance comparison as a mediator of relationships between intrasexual competition and our cosmetic surgery variables (i.e., positive attitude toward surgery, perceived risk, and desired lifetime spending), we first had to determine if individuals who scored higher in intrasexual competitiveness were indeed more likely to make physical appearance comparisons. Results indicated that for women $(\mathrm{b}=.31, p$ $<.001)$ and men $(\mathrm{b}=.37, p<.001)$, intrasexual competition statistically-significantly predicted physical appearance comparison.

Table 1. Descriptive statistices for study variables. CS = Cosmetic Surgery.

\begin{tabular}{|c|c|c|c|c|c|c|c|c|}
\hline & \multicolumn{4}{|c|}{ Women } & \multicolumn{4}{|c|}{ Men } \\
\hline & $\mathrm{N}$ & M & SD & Range & $\mathrm{N}$ & M & SD & Range \\
\hline Intrasexual competition & 191 & 2.51 & 1.05 & 4.67 & 104 & 2.67 & 0.99 & 4.00 \\
\hline Appearance comparison & 191 & 3.24 & .70 & 3.20 & 104 & 2.79 & 0.70 & 3.20 \\
\hline CS attitude & 190 & 2.72 & 1.39 & 6.00 & 102 & 2.25 & 0.95 & 4.27 \\
\hline CS spending & 189 & 1.78 & 1.14 & 5.00 & 103 & 1.37 & 0.85 & 4.00 \\
\hline CS risk & 189 & 3.55 & .49 & 2.50 & 103 & 3.35 & 0.46 & 1.83 \\
\hline
\end{tabular}


We explored the hypothesis that intrasexual competition would predict a positive attitude toward cosmetic surgery. For women, results showed that intrasexual competition had a total effect on attitude toward cosmetic surgery of $\mathrm{b}=.47, p<.001$. However, when we included physical appearance comparison in the model, results showed that the direct effect of intrasexual competition upon attitude toward cosmetic surgery was significantly reduced, $\mathrm{b}=.25, p<.05$, bootstrapping: $95 \% \mathrm{LL}=.11,95 \% \mathrm{UL}=.32$, indicating partial mediation of the effect. In the mediation model, physical appearance comparison significantly predicted positive attitudes toward cosmetic surgery, $\mathrm{b}=.70, p<.0001$. The mediation model contributed .22 toward explained variance $\left(R_{a d j}^{2}\right)$.

For men, results showed that intrasexual competition had a total effect on attitude toward cosmetic surgery of $\mathrm{b}=.24, p<.01$. However, when we included physical appearance comparison in the model as a mediating variable, results showed that the direct effect of intrasexual competition upon attitude toward cosmetic surgery was significantly reduced, $\mathrm{b}=.13$, n.s., bootstrapping: $95 \% \mathrm{LL}=.01,95 \% \mathrm{UL}=.24$, indicating a full mediation of the effect. In the mediation model, physical appearance comparison significantly predicted positive attitudes toward cosmetic surgery, $\mathrm{b}=.32, p<.05$. The mediation model contributed .11 toward explained variance $\left(R_{a d j}^{2}\right)$.

Next, we examined the hypothesis that intrasexual competition would predict an increased desire to spend money on cosmetic surgery. For women, results showed that intrasexual competition had a total effect on cosmetic surgery spending of $\mathrm{b}=.26, p<.01$. However, when we included physical appearance comparison in the model we found that the direct effect of intrasexual competition upon cosmetic surgery spending was reduced to non-significance, $\mathrm{b}=.08$, n.s. Physical appearance comparison significantly predicted cosmetic surgery spending, $\mathrm{b}=.60, p<.001$, and fully-mediated (i.e., reduced to non-significance) the link between intrasexual competition and cosmetic surgery spending (bootstrapping: $95 \% \mathrm{LL}=.09,95 \% \mathrm{UL}=.31$ ). The mediation model contributed 14 toward explained variance $\left(R_{a d j}^{2}\right)$.

Results were again similar for men, showing that intrasexual competition had a total effect on cosmetic surgery spending of $\mathrm{b}=.20, p<.05$. However, when we included physical appearance comparison in the model we found that the direct effect of intrasexual competition upon cosmetic surgery spending was again reduced to non-significance, $b=.09$, n.s. Physical appearance comparison significantly predicted cosmetic surgery spending, $\mathrm{b}=.29, p<.05$, and fully-mediated (i.e., reduced to non-significance) the link between intrasexual competition and cosmetic surgery spending (bootstrapping: 95\% LL $=.02$, 95\% UL $=.30$ ). The mediation model contributed .08 toward explained variance $\left(R_{a d j}^{2}\right)$.

Next, we examined the hypothesis that intrasexual competition would predict lower perceived cosmetic surgery risk. However, contrary to our expectations, for women results showed that neither intrasexual competition $\mathrm{b}=-.01$, n.s., nor physical appearance comparison, $\mathrm{b}=-.05$, n.s. predicted cosmetic surgery risk and the mediation model was not significant (bootstrapping: $95 \% \mathrm{LL}=-.06,95 \% \mathrm{UL}=.02$ ). For men, results similarly showed that neither intrasexual competition $\mathrm{b}=-.03$, n.s., nor physical appearance comparison, $\mathrm{b}=-.06$, n.s. predicted cosmetic surgery risk. The mediation model was statistically non-significant (bootstrapping: 95\% LL = $-.08,95 \% \mathrm{UL}=.05)$.

\section{Discussion}

Results of the present study confirmed that women more than men held more positive attitudes toward cosmetic surgery and were willing to spend more on cosmetic surgery over their lifetime. The importance of physical attractiveness as a cue to health and fertility is particularly salient in men's mate choices. Some researchers suggest that this gender difference is rooted in the differential mating challenges faced by men and women. Men's primary procreative constraint is accessing reproductively viable women, whereby "mating with less fertile or less reproductively viable women can be costly in lost opportunities, especially in mating systems that require prolonged courtship and discourage simultaneous multiple matings” (Buss, 1988: p. 617). Indeed, research has found that men more than women emphasize the need for a partner to be physically-attractive (Li, Bailey, Kenrick, \& Linsenmeier, 2002); a robust sex difference that has been observed cross-culturally (Buss et al., 1990). Given that individuals tend to compete intrasexually on dimensions considered important by the opposite sex (Buss, 1988), it is not surprising that women held more positive attitudes toward cosmetic surgery, and were willing to spend more than men. Indeed, in 2013 in the United States, 91\% of all cosmetic surgeries were performed on women (American Society of Plastic Surgeons, 2013). However, as described earlier, men's physical appearance can also convey important information regarding their phenotypic and genotypic condition, and women also base their mating decisions on men's physical attractiveness (albeit to a lesser degree in a long-term 
mating context). Therefore, men might also benefit from competing in the realm of physical attractiveness.

The five most common cosmetic surgical procedures in the United States are: breast augmentation, nose reshaping, eyelid surgery, liposuction, and facelift (American Society for Plastic Surgeons, 2013). The popularity of these elective procedures is not surprising given that symmetrical and attractive facial features and a healthy BMI and waist-to-hip ratio have been linked to health and reproductive viability (e.g., Hamilton-Fairley et al., 1992; Rhodes et al., 2005; Rhodes et al., 2001; Singh, 1993), and are also signs of physical attractiveness (Shackelford \& Larsen, 1999; Tovée \& Cornelissen, 2001). Researchers have observed that individuals often compete with members of the same sex on mating-relevant dimensions that are valued by the opposite sex (Buss, 1988), suggesting that cosmetic surgery may be, in part, a function of intrasexual competition. Results of the present study showed that both women and men who scored high on intrasexual competitiveness held more positive attitudes toward cosmetic surgery and were willing to spend more on cosmetic surgery over the lifetime, supporting Hypothesis 1.

Physical appearance comparisons had a significant mediating effect upon each of these relationships; with model effect sizes ranging between $8 \%$ and 22\% $\left(R_{a d j}^{2}\right)$, supporting Hypothesis 2. Social comparisons may be an important correlate of intrasexual competition (Buunk \& Fisher, 2009) in that they allow individuals to determine what others will find attractive, and where they stand on those dimensions (Gilbert et al., 1995). The capacity to make social comparisons evolved in an environment very different from that of modern humans. Today, we experience pervasive exposure to morphological ideals (for instance, in digital and print media). Exposure to attractive others can affect our mate-preferences and interests (Kenrick, Neuberg, Zierk, \& Krones, 1994) as well as our own body satisfaction (Hawkins, Richards, Granley, \& Stein, 2004). Moreover, media exposure has been found to influence attitudes and intentions surrounding cosmetic surgery (Delinsky, 2005; Henderson-King \& Brooks, 2009). It is interesting that our mediation model applied to men for both attitudes toward cosmetic surgery and willingness to spend on cosmetic surgery. Although women were, in general, more favorable toward cosmetic surgery along these indices, this finding nevertheless reflects the budding pressure experienced by men to exhibit the aspects of physical appearance deemed to be most attractive. This is not surprising given that men's appearance may signal sperm quality and health. Moreover, in terms of social status and resource acquisition, physically-attractive men have been found to have higher starting salaries and to earn more over time (Hanson Frieze, Olson, \& Russell, 2006). Most studies on cosmetic surgery have focused solely on women. The study of men's behavior in this domain may be an interesting and fruitful area of research.

Contrary to our expectations, intrasexual competition and physical appearance comparison did not correlate with lower perceptions of cosmetic surgery risk for either women or men. This speaks to the power of intrasexually-competitive appearance enhancement motives. Intrasexually-competitive individuals engaged in more appearance-based social comparisons, and were more favorable toward cosmetic surgery spending even though they perceive the same level of risk as less-competitive individuals. It appears that the perceived risk of cosmetic surgery is considered more acceptable or worthwhile among highly intrasexually-competitive individuals. This finding might ultimately be important to public awareness campaigns aimed at preventing unnecessary health consequences associated with cosmetic surgery. For instance, some advertisements for cosmetic surgery have been criticized for failing to clearly specify the degree of commitment and aftercare involved in some procedures (United Kingdom Health Committee-sixteenth report, 2012). Based upon the current findings, it seems likely that such warnings would be challenged to deter intrasexually-competitive cosmetic surgery-seekers.

The sample used in the present study was limited in terms of the age range and ethnic distribution of participants. Our study had a restricted age range of participants between 16- and 31-year of age, and primarily of Caucasian descent. Most cosmetic procedures are undertaken by women in their early 40's to mid-50's (American Society of Plastic Surgeons, 2013), perhaps due to normal ageing-related influences on appearance in conjunction with greater income and opportunity to undergo cosmetic procedures. Interestingly, most women will become unlikely to conceive by their mid-40's (American Society for Reproductive Medicine, 2012). It would be interesting to examine whether intrasexual competition motives correlate with these women's decision to have cosmetic surgery as strongly.

This study was also limited by the correlational nature of its design. Future research would benefit from employing an experimental paradigm, perhaps by priming intrasexual competitiveness (e.g., Hill \& Durante, 2011) and exploring subsequent changes in cosmetic surgery attitudes and intentions. Longitudinal analyses would also be beneficial in determining whether attitudes and intentions for cosmetic surgery translate into action among intrasexually-competitive individuals. It would also be interesting to examine whether those who desire cos- 
metic surgery hold skewed perceptions of what members of the opposite sex desires in a mate. We suspect that these individuals will over-emphasize morphological characteristics, and underestimate personality and interpersonal variables, which previous research has shown to be highly important in both men's and women's mate preferences (e.g., Buss et al., 1990).

\section{Conclusion}

The rapid growth in cosmetic surgical procedures seems to reflect the public's blooming acceptance of cosmetic surgery as a mode of self-improvement (Delinsky, 2005). Given the multifarious potential costs associated with elective cosmetic surgery procedures, it is very important that researchers gain a more comprehensive understanding of the motives that underlie these decisions. Results of the current study suggest that enhancement of one's physical appearance via cosmetic surgery may be a tactic for intrasexual competition. Results confirmed that social comparison mediated the links between intrasexual competition and cosmetic surgery attitudes and desired spending.

\section{References}

Abed, R. T. (1998). The Sexual Competition Hypothesis for Eating Disorders. British Journal of Medical Psychology, 71, 525-547. http://dx.doi.org/10.1111/j.2044-8341.1998.tb01007.x

Alsarraf, R., Larrabee, W. F., Anderson, S., Murakami, C. S., \& Johnson, C. M. (2001). Measuring Cosmetic Facial Plastic Surgery Outcomes: A Pilot Study. Archives of Facial Plastic Surgery, 3, 198-201. http://dx.doi.org/10.1001/archfaci.3.3.198

American Society of Plastic Surgeons (2013). ASPS National Clearinghouse of Plastic Surgery Procedural Statistics. http://www.plasticsurgery.org/news/plastic-surgery-statistics/2013.html

American Society for Reproductive Medicine (2012). Age and Fertility: A Guide for Patients. https://www.asrm.org/Booklet_Age_and_Fertility/

Arnocky, S., Sunderani, S., Miller, J., \& Vaillancourt, T. (2012). Jealousy Mediates the Relationship between Attractiveness Comparison and Females’ Indirect Aggression. Personal Relationships, 19, 290-303. http://dx.doi.org/10.1111/j.1475-6811.2011.01362.x

Arnocky, S., \& Vaillancourt, T. (2012). A Multi-Informant Longitudinal Study on the Relationship between Aggression, Peer Victimization, and Dating Status in Adolescence. Evolutionary Psychology, 10, 253-270.

Baron, R., \& Kenny, D. (1986). The Moderator-Mediator Variable Distinction in Social Psychological Research: Conceptual, Strategic, and Statistical Considerations. Journal of Personality and Social Psychology, 51, 1173-1182.

http://dx.doi.org/10.1037/0022-3514.51.6.1173

Borah, G., Rankin, M., \& Wey, P. (1999). Psychological Complications in 281 Surgery Practices. Plastic and Reconstructive Surgery, 104, 1241-1246. http://dx.doi.org/10.1097/00006534-199910000-00002

Buss, D. M. (1988). The Evolution of Human Intrasexual Competition: Tactics of Mate Attraction. Journal of Personality and Social Psychology, 54, 616-628. http://dx.doi.org/10.1037/0022-3514.54.4.616

Buss, D. M., Abbott, M., Angleitner, A., Asherian, A., Biaggio, A., Blanca-Villasenor, A., \& Yang, K. S. (1990). International Preferences in Selecting Mates: A Study of 37 Cultures. Journal of Cross-Cultural Psychology, 21, 5-47. http://dx.doi.org/10.1177/0022022190211001

Buss, D. M., \& Schmitt, D. P. (1993). Sexual Strategies Theory: An Evolutionary Perspective on Human Mating. Psychological Review, 100, 204-232. http://dx.doi.org/10.1037/0033-295X.100.2.204

Buunk, B. P., \& Fisher, M. L. (2009). Individual Differences in Intrasexual Competition. Journal of Evolutionary Psychology, 7, 37-48. http://dx.doi.org/10.1556/JEP.7.2009.1.5

Cash, T. F., \& Horton, C. E. (1983). Aesthetic Surgery: Effects of Rhinoplasty on the Social Perception of Patients by Others. Plastic and Reconstructive Surgery, 72, 543-548. http://dx.doi.org/10.1097/00006534-198310000-00025

Castle, D. J., Honigman, R. J., \& Phillips, K. A. (2002). Does Cosmetic Surgery Improve Psychosocial Wellbeing? The Medical Journal of Australia, 176, 601-604.

Davis, K. (1995). Reshaping the Female Body: The Dilemma of Cosmetic Surgery. New York: Routledge.

Delinsky, S. S. (2005). Cosmetic Surgery: A Common and Accepted Form of Self-Improvement? Journal of Applied Social Psychology, 35, 2012-2028. http://dx.doi.org/10.1111/j.1559-1816.2005.tb02207.x

Dull, D., \& West, C. (1991). Accounting for Cosmetic Surgery: The Accomplishment of Gender. Social Problems, 38, 54-70. http://dx.doi.org/10.2307/800638 
Festinger, L. (1954). A Theory of Social Comparison Processes. Human Relations, 7, 117-140. http://dx.doi.org/10.1177/001872675400700202

Faer, L. M., Hendriks, A., Abed, R. T., \& Figueredo, A. J. (2005). The Evolutionary Psychology of Eating Disorders: Female Competition for Mates or for Status? Psychology and Psychotherapy, 78, 397-417. http://dx.doi.org/10.1348/147608305X42929

Gilbert, P., Price, J., \& Allan, S. (1995). Social Comparison, Social Attractiveness and Evolution: How Might They Be Related? New Ideas in Psychology, 13, 149-165. http://dx.doi.org/10.1016/0732-118X(95)00002-X

Gabriel, S. E., Woods, J. E., O’Fallon, W. M., Beard, C. M., Kurland, L. T., \& Melton, L. J. (1997). Complications Leading to Surgery after Breast Implantation. New England Journal of Medicine, 336, 677-682. http://dx.doi.org/10.1056/NEJM199703063361001

Grazer, F., \& de Jong, R. H. (2000). Fatal Outcomes from Liposuction: Census Survey of Cosmetic Surgeons. Plastic and Reconstructive Surgery, 105, 436-446.

Hamilton-Fairley, D., Kiddy, D., Watson, H., \& Franks, S. (1992). Association of Moderate Obesity with a Poor Pregnancy Outcome in Women with Polycystic Ovary Syndrome Treated with Low Dose Gonadotrophin. BJOG: An International Journal of Obstetrics \& Gynaecology, 99, 128-131. http://dx.doi.org/10.1111/j.1471-0528.1992.tb14470.x

Hanson Frieze, I., Olson, J. E., \& Russell, J. (2006). Attractiveness and Income for Men and Women in Management. Journal of Applied Social Psychology, 21, 1039-1057. http://dx.doi.org/10.1111/j.1559-1816.1991.tb00458.x

Hawkins, N., Richards, P. S., Granley, H. M., \& Stein, D. M. (2004). The Impact of Exposure to the Thin-Ideal Media Image on Women. Eating Disorders: The Journal of Treatment \& Prevention, 12, 35-50. http://dx.doi.org/10.1080/10640260490267751

Henderson, J. J. A., \& Anglin, J. M. (2003). Facial Attractiveness Predicts Longevity. Evolution and Human Behavior, 24, 351-365. http://dx.doi.org/10.1016/S1090-5138(03)00036-9

Henderson-King, D., \& Brooks, K. D. (2009). Materialism, Sociocultural Appearance Messages, and Paternal Attitudes Predict College Women's Attitudes about Cosmetic Surgery. Psychology of Women Quarterly, 33, 133-142.

http://dx.doi.org/10.1111/j.1471-6402.2008.01480.x

Henderson-King, D., \& Henderson-King, E. (2005). Acceptance of Cosmetic Surgery: Scale Development and Validation. Body Image, 2, 137-149. http://dx.doi.org/10.1016/j.bodyim.2005.03.003

Hill, S. E., \& Durante, K. M. (2011). Courtship, Competition, and the Pursuit of Attractiveness: Mating Goals Facilitate Health-Related Risk Taking and Strategic Risk Suppression in Women. Personality and Social Psychology Bulletin, 37, 383-394. http://dx.doi.org/10.1177/0146167210395603

Kenrick, D. T., Neuberg, S. L., Zierk, K. L., \& Krones, J. M. (1994). Evolution and Social Cognition: Contrast Effects as a Function of Sex, Dominance, and Physical Attractiveness. Personality and Social Psychology Bulletin, 20, $210-217$. http://dx.doi.org/10.1177/0146167294202008

Li, N. P., Bailey, M. J., Kenrick, D. T., \& Linsenmeier, J. A. W. (2002). The Necessities and Luxuries of Mate Preferences: Testing the Tradeoffs. Journal of Personality and Social Psychology, 82, 947-955. http://dx.doi.org/10.1037/0022-3514.82.6.947

Li, N. P., Smith, A. R., Griskevicius, V., Cason, M. J., \& Bryan, A. (2010). Intrasexual Competition and Eating Restriction in Heterosexual and Homosexual Individuals. Evolution and Human Behavior, 31, 365-372. http://dx.doi.org/10.1016/j.evolhumbehav.2010.05.004

MacKinnon, D. P., Lockwood, C. M., Hoffman, J. M., West, S. G., \& Sheets, V. (2002). A Comparison of Methods to Test Mediation and Other Intervening Variable Effects. Psychological Methods, 7, 83-104. http://dx.doi.org/10.1037/1082-989X.7.1.83

Maner, J. K., Gailliot, M. T., Rouby, D. A., \& Miller, S. L. (2007). Can’t Take My Eyes off You: Attentional Adhesion to Mates and Rivals. Journal of Personality and Social Psychology, 93, 389-401. http://dx.doi.org/10.1037/0022-3514.93.3.389

Markey, C. M., \& Markey, P. M. (2009). Correlates of Young Women’s Interest in Obtaining Cosmetic Surgery. Sex Roles, 61, 158-166. http://dx.doi.org/10.1007/s11199-009-9625-5

Metwally, M., Ong, K. J., Ledger, W. L., \& Li, T. C. (2008). Does High Body Mass Index Increase the Risk of Miscarriage after Spontaneous and Assisted Conception? A Meta-Analysis of the Evidence. Fertility and Sterility, 90, 714-726. http://dx.doi.org/10.1016/j.fertnstert.2007.07.1290

Nabi, R. L. (2009). Cosmetic Surgery Makeover Programs and Intentions to Undergo Cosmetic Enhancements: A Consideration of Three Models of Media Effects. Human Communication Research, 35, 1-27. http://dx.doi.org/10.1111/j.1468-2958.2008.01336.x

Park, L. E., Calogero, R. M., Harwin, M. J., \& DiRaddo, A. (2009). Predicting Interest in Cosmetic Surgery: Interactive Effects of Appearance-Based Rejection Sensitivity and Negative Appearance Comments. Body Image, 6, 186-193. 
http://dx.doi.org/10.1016/j.bodyim.2009.02.003

Rankin, M., Borah, G. L., Perry, A. W., \& Wey, P. D. (1998). Quality-of-Life Outcomes after Cosmetic Surgery. Plastic and Reconstructive Surgery, 102, 2139-2147. http://dx.doi.org/10.1097/00006534-199811000-00053

Rhodes, G., Simmons, L. W., \& Peters, M. (2005). Attractiveness and Sexual Behavior: Does Attractiveness Enhance Mating Success? Evolution and Human Behavior, 26, 186-201. http://dx.doi.org/10.1016/j.evolhumbehav.2004.08.014

Rhodes, G., Zebrowitz, L. A., Clark, A., Kalick, S. M., Hightower, A., \& McKay, R. (2001). Do Facial Averageness and Symmetry Signal Health? Evolution and Human Behavior, 22, 31-46. http://dx.doi.org/10.1016/S1090-5138(00)00060-X

Sarwer, D. B., Cash, T. F., Magee, L., Williams, E. F., Thompson, J. K., Roehrig, M. et al. (2005). Female College Students and Cosmetic Surgery: An Investigation of Experiences, Attitudes, and Body Image. Plastic and Reconstructive Surgery, 115, 931-938. http://dx.doi.org/10.1097/01.PRS.0000153204.37065.D3

Sarwer, D. B., Gibbons, L. M., Magee, L., Baker, J. L., Casas, L. A., Glat, P. M., Gold, A. H., Jewell, M. L., LaRossa, D., Nahai, F., \& Young, V. L. (2005). A Prospective, Multi-Site Investigation of Patient Satisfaction and Psychosocial Status Following Cosmetic Surgery. Aesthetic Surgery Journal, 25, 263-269. http://dx.doi.org/10.1016/j.asj.2005.03.009

Sarwer, D. B., Wadden, T. A., Pertschuk, M. J., \& Whitaker, L. A. (1998). Body Image Dissatisfaction and Body Dysmorphic Disorder in 100 Cosmetic Surgery Patients. Plastic \& Reconstructive Surgery, 101, 1644-1649. http://dx.doi.org/10.1097/00006534-199805000-00035

Shackelford, T. K., \& Larsen, R. J. (1999). Facial Attractiveness and Physical Health. Evolution and Human Behavior, 20, 71-76. http://dx.doi.org/10.1016/S1090-5138(98)00036-1

Singh, D. (1993). Adaptive Significance of Female Physical Attractiveness: Role of Waist-to-Hip Ratio. Journal of Personality and Social Psychology, 65, 293-307. http://dx.doi.org/10.1037/0022-3514.65.2.293

Singh, D., \& Randall, P. K. (2007). Beauty Is in the Eye of the Plastic Surgeon: Waist-Hip Ratio (WHR) and Women's Attractiveness. Personality and Individual Differences, 43, 329-340. http://dx.doi.org/10.1016/j.paid.2006.12.003

Soler, C., Nunez, M., Gutierrez, R., Nunez, J., Medina, P., Sancho, M., Álvarez, J., \& Nunez, A. (2003). Facial Attractiveness in Men Provides Clues to Semen Quality. Evolution \& Human Behavior, 24, 199-207. http://dx.doi.org/10.1016/S1090-5138(03)00013-8

Sunderani, S., Arnocky, S., \& Vaillancourt, T. (2013). Individual Differences in Mate Poaching: An Examination of Hormonal, Dispositional, and Behavioral Mate-Value Traits. Archives of Sexual Behavior, 42, 533-542. http://dx.doi.org/10.1007/s10508-012-9974-y

Swami, V. (2009). Body Appreciation, Media Influence, and Weight Status Predict Consideration of Cosmetic Surgery among Female Undergraduates. Body Image, 6, 315-317. http://dx.doi.org/10.1016/j.bodyim.2009.07.001

Swami, V. (2010). Translation and Validation of the Malay Acceptance of Cosmetic Surgery Scale. Body Image, 7, $372-375$. http://dx.doi.org/10.1016/j.bodyim.2010.07.005

Swami, V., Chamorro-Premuzic, T., Bridges, S., \& Furnham, A. (2009). Acceptance of Cosmetic Surgery: Personality and Individual Difference Predictors. Body Image, 6, 7-13. http://dx.doi.org/10.1016/j.bodyim.2008.09.004

Symons, D. (1979). The Evolution of Human Sexuality. New York: Oxford University Press.

Thompson, J. K., Heinberg, L., \& Tantleff, S. (1991). The Physical Appearance Comparison Scale (PACS). The Behavior Therapist, 14, 174.

Thornhill, R., \& Alcock, J. (1983). The Evolution of Insect Mating Systems. Cambridge: Harvard University Press. http://dx.doi.org/10.4159/harvard.9780674433960

Thornton, B., Ryckman, R. M., \& Gold, J. A. (2013). Competitive Orientations and Women's Acceptance of Cosmetic Surgery. Psychology, 4, 67-72. http://dx.doi.org/10.4236/psych.2013.41009

Thorpe, S. J., Ahmed, B., \& Steer, K. (2004). Reasons for Undergoing Cosmetic Surgery: A Retrospective Study. Sexualities, Evolution \& Gender, 6, 75-96. http://dx.doi.org/10.1080/14616660412331303857

Tovée, M. J., \& Cornelissen, P. L. (2001). Female and Male Perceptions of Female Physical Attractiveness in Front-View and Profile. British Journal of Psychology, 92, 391-402. http://dx.doi.org/10.1348/000712601162257

United Kingdom Health Committee (2012). Sixteenth Report: PIP Breast Implants and Regulation of Cosmetic Interventions. www.publications.parliament.uk/pa/cm201012/cmselect/cmhealth/1816/181602.htm

Weeden, J., \& Sabini, J. (2005). Physical Attractiveness and Health in Western Societies: A Review. Psychological Bulletin, 131, 635-653. http://dx.doi.org/10.1037/0033-2909.131.5.635

Yoho, R. A., Romaine, J. J., \& O’Neil, D. (2005). Review of the Liposuction, Abdominoplasty, and Face-Lift Mortality and Morbidity Risk Literature. Dermatologic Surgery, 31, 733-743. http://dx.doi.org/10.1097/00042728-200507000-00001 
Scientific Research Publishing (SCIRP) is one of the largest Open Access journal publishers. It is currently publishing more than 200 open access, online, peer-reviewed journals covering a wide range of academic disciplines. SCIRP serves the worldwide academic communities and contributes to the progress and application of science with its publication.

Other selected journals from SCIRP are listed as below. Submit your manuscript to us via either submit@scirp.org or Online Submission Portal.
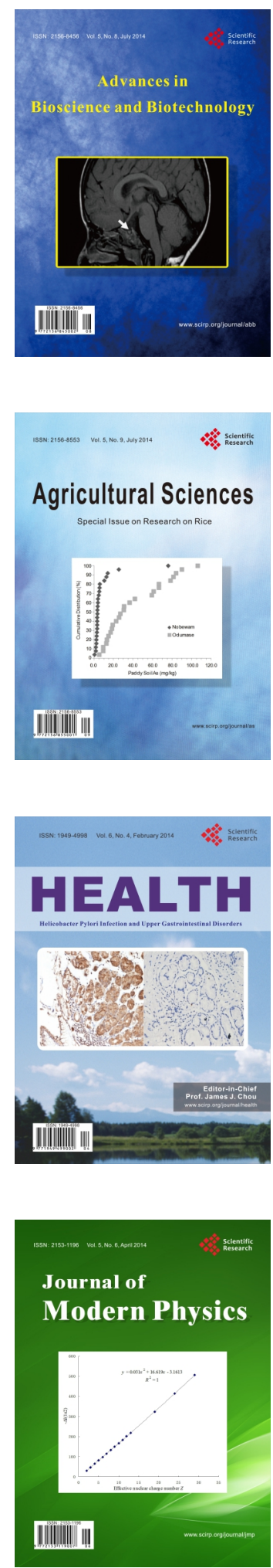
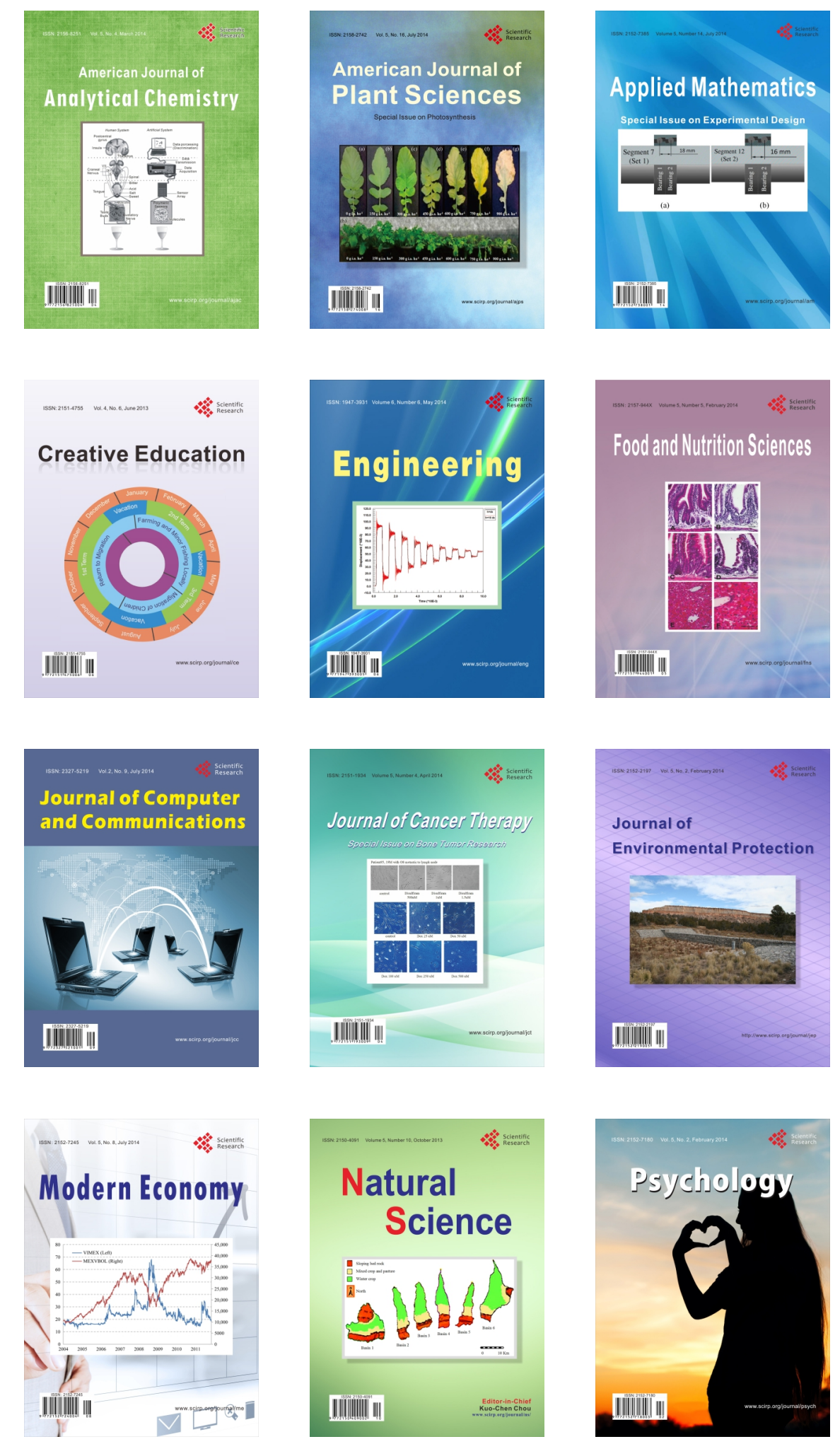